\title{
Water-air regenerative heat exchanger with increased heat exchange efficiency
}

\author{
Sergey Batukhtin*, Andrey Batukhtin, and Marina Baranovskaya \\ EDP Transbaikal State University, 672039 Chita, Russia
}

\begin{abstract}
According to experts' forecasts, by 2040 the global demand for energy will increase by $37 \%$, and renewable energy sources in the next 20 years will become the fastest growing segment of the world energy, their share in the next decade will grow by about one and a half times. Solar energy is the fastest growing industry among all non-conventional energy sources and is gaining the highest rates of development in comparison with other renewable energy sources. In this article, the authors provide an overview of the technologies that increase the efficiency and productivity of solar panels, only the investigated methods are described that can speed up the process of introducing solar energy instead of traditional. All the methods described can increase the efficiency of systems that are based on the use of the sun as the main source of energy. The authors presented and described the scheme of a solar-air thermal power plant, which will improve energy efficiency through the use of a regenerative air solar collector with increased heat transfer efficiency. Strengthening will be achieved through the use of hemispherical depressions on the surface that receives solar radiation. A schematic diagram is given and the principle of operation of such a solar collector is described in detail. A comparative calculation of the intensification of the solar collector with the use of depressions and without the use as modernization was carried out, on the basis of which a conclusion was made about the efficiency of using this type of solar collector and the economic effect from the application of this method. A description of the method for calculating the solar collector is given, thanks to which this development can be used and implemented in existing heating and hot water supply systems.
\end{abstract}

\section{Introduction}

Today, non-traditional and renewable energy sources are very popular all over the world. According to experts' forecasts, renewable energy sources in the next 20 years will become the fastest growing segment of the world energy, their share in the next decade will grow by about one and a half times [1]. Around the world, solar energy is gaining the highest rate of development in comparison with other types of renewable energy sources. This is due to a number of factors: environmental friendliness of the technology, high reliability of the solar battery, autonomy of power supply to the energy consumer, the presence of an endless source of energy, as well as the absence of noise during operation. Germany leads the world in the

\footnotetext{
* Corresponding author: batuhtin1@mail.ru
} 
use of solar energy, followed by China, Italy, Japan, the USA, Spain, France and other countries. [2]

The policy of countries in which non-traditional energy is actively developing, in particular solar, is aimed at the development and widespread introduction of renewable energy sources into people's lives. For example, China, the United States and the European Union are already actively studying the power of devices and mechanisms from solar energy. This means that in developed countries not only the issue of introducing solar energy instead of traditional energy sources is being studied, but also the issues of modernizing and improving existing methods. Therefore, the scientists of these countries are faced with the question of studying and researching various ways by which it is possible not only to increase the efficiency of solar power plants, but also to increase their power and energy intensity.

There are many possible ways to improve the operation of solar collectors - the use of various kinds of concentrators, optimization of tracking the position of the sun, the choice of the tilt angle and orientation of the solar collector. In addition to optimizing the methods for positioning the solar collector, methods for improving their design are also widely studied. The possibility of using new materials in the production of various elements is being studied; designs of polymer solar collectors, which are twice cheaper than conventional ones, are proposed. A large number of modern developments are devoted to the issue of increasing the efficiency of autonomous heat supply installations based on solar power plants [3-5]. Foreign authors studying solar energy pay attention to the assessment of solar radiation [6-9]. There are several ways to assess data on solar radiation fluxes: analytical; direct measurements on site; long-term measurements using a unified technique at meteorological stations.

One of the most urgent is the issue of researching algorithms based on the analytical interpretation of the sun's motion $[10,11]$. Some authors for this method use the function of the average monthly intensity of solar radiation, but this approach is ineffective and is subject to serious criticism from researchers since hourly fluctuations are not taken into account [1022].

All the necessary parameters of a specific geographic point can be determined by calculation. The general laws considered in [23] determine the parameters of the Sun's motion over the horizon, the energy [24, 25] and spectral characteristics of radiation [26-28]. In [29], the thermodynamic parameters of effective absorption are considered. The Universities of Minnesota and Hanevelt have considered the coefficients of effective absorption of the normal spectrum of solar radiation for the main selective coatings [30-32].

The latter method - direct measurement on site - is the most laborious of all, but it has been used by a number of researchers, both foreign [33-36] and domestic [37]. At present, the World Radiation Data Center (WRDC) has an information retrieval system with an archive and a systematically updated database on the components of the radiation balance of the world actinometric network. [38, 39] The main elements of this network are actinometric installations [40-43], which determine the parameters of direct and scattered solar radiation. In addition, there are private databases of renewable energy resources [44-50]. Much attention is paid to solar installations of a separate type, where the accumulator is located separately from the collector $[51,52]$, the most common of them are vacuum tubular solar collectors, which occupy more than $60 \%$ of the market [53]. One of the main tasks of the development of solar energy is to increase the capacity of solar plants, which will lead to an increase in their economic performance [54-57]. Self-draining solar heat supply systems are also being actively studied, a feature of which is the emptying of solar collectors from the coolant when the solar circuit pump stops in a special tank / storage tank.

A significant number of foreign developments are devoted to the development of the "Solar House" system, the essence of which is that electricity, water supply and heating are provided by the energy of the sun. In the United States, a special competition has even been established that brings together 20 international university teams in the fight to create the 
most attractive and energy efficient solar houses, which also significantly reduce greenhouse gas emissions into the atmosphere [58-62].

All of the above research and development is only a small part devoted to the study of the issue of the development of unconventional and renewable energy sources, namely solar energy. Such a great interest in this problem once again confirms the relevance of the study and use of RES in the modern world.

\section{Research methodology}

This article proposes a method of using a regenerative air solar collector with increased heat transfer efficiency. This heat exchanger (Fig. 1) is designed to improve the efficiency of the implementation of the scheme of an energy-efficient solar-air heating installation. A distinctive feature of this heat exchanger is the ability to simultaneously heat two types of heat transfer fluids. It is proposed to use hemispherical recesses as intensifiers. A detailed description of this type of intensifier is presented in [64]. 

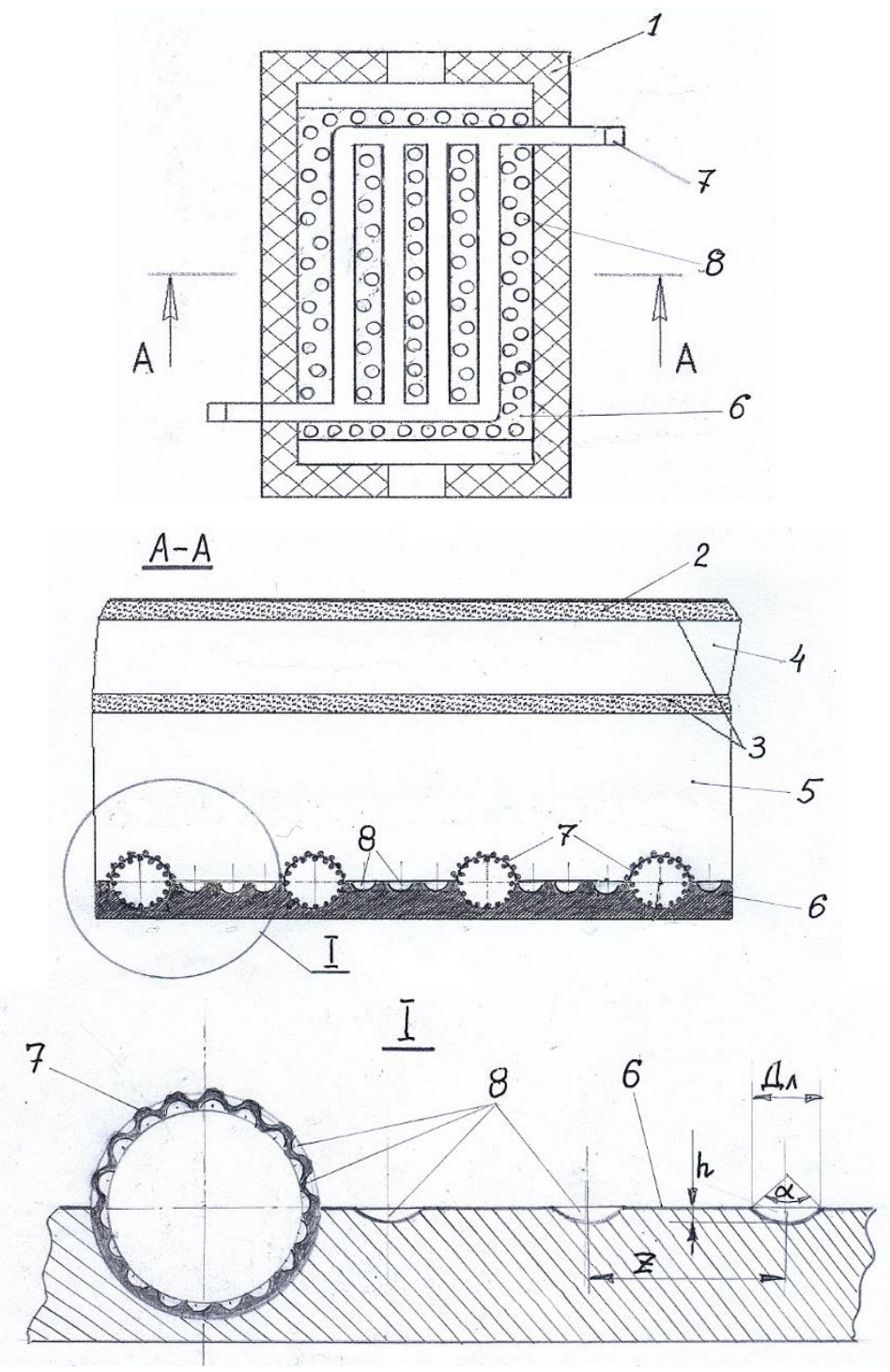

Fig. 1. Water-air regenerative heat exchanger with increased heat exchange efficiency:

1 - insulation; 2, 3 - glass; 4 - vacuum; 5 - air passage; 6 - sun-perceiving surface; 7 - tube; 8 spherical intensifiers

The operation of the solar collector with the use of hemispherical depressions is as follows (Fig. 1): the radiation of the Sun, passing through the glass, heats the absorber, which in turn heats the gaseous medium (air) moving in the gas heating cavity 5 , while the hemispherical depressions 8 on the sun-perceiving surface 6 will contribute to a significant intensification of heat transfer. The coolant in the collector circulates through a harp-shaped pipe system, and since they are recessed by $50 \%$ into the sun-sensing plate, they will heat up, and the hemispherical recesses applied to the inner surface of the tubes will also contribute to the intensification of heat transfer. An increase in the efficiency of heat transfer in the developed collector is determined by a local increase in the heat transfer coefficient and an increase in the area. The growth of the heat transfer coefficient can be determined on the basis of experimental data, or by calculation. 


\section{Research results}

To understand how effective intensification is, it is necessary to calculate the daily heat absorption of a flat water-air collector with and without modernization [64]. The calculation was made using [65] under comparable conditions.

Climatological data: Chita: longitude - 113 hours 23 minutes, latitude - 52 hours 6 minutes; date October 1, 2013

Surface direction: tilt angle to the horizon - 45 degrees; azimuth direction $180 \mathrm{deg}$. $2 \mathrm{~mm}$.

Plate: plate dimensions are taken: $1000 * 100 * 10 \mathrm{~mm}$, material - copper, wall thickness

Tubes: quantity 10 pcs., diameter $25 \mathrm{~mm}$, material - copper, wall thickness $1 \mathrm{~mm}$; coverage share $50 \%$; thermal interface material - tin, layer thickness 500 microns.

Absorber: coloring - matt black paint (absorption rate 95, blackness 5, selectivity 0.4 );

External insulation: glass - two layers, thickness $1 \mathrm{~mm}$, attenuation coefficient 0.41 / $\mathrm{mm}$; air passage size $30 \mathrm{~mm}$.

Air parameters: inlet air temperature $00 \mathrm{C}$; air consumption - $100.0 \mathrm{~m} 3 / \mathrm{h}$.

The results of calculating the daily heat perception of a flat water-air collector are summarized in Table 1.

Table 1. Results of calculating a flat reservoir without stimulation. Inlet air temperature / ambient temperature $0^{\circ} \mathrm{C}$

\begin{tabular}{|c|c|c|}
\hline № & $\begin{array}{c}\text { The local } \\
\text { time }\end{array}$ & $\begin{array}{c}\text { Warmth is } \\
\text { beneficially } \\
\text { perceived } \\
\text { collector, W }\end{array}$ \\
\hline 1 & $9: 00$ & 0 \\
\hline 2 & $10: 00$ & 150 \\
\hline 3 & $11: 00$ & 362 \\
\hline 4 & $12: 00$ & 550 \\
\hline 5 & $13: 00$ & 625 \\
\hline 6 & $14: 00$ & 670 \\
\hline 7 & $15: 00$ & 655 \\
\hline 8 & $16: 00$ & 585 \\
\hline 9 & $17: 00$ & 455 \\
\hline 10 & $18: 00$ & 260 \\
\hline 11 & $19: 00$ & 50 \\
\hline 12 & $20: 00$ & 0 \\
\hline 13 & Total per day & 4362 \\
\hline
\end{tabular}

When calculating the daily heat perception of a regenerative water-air heat exchanger with an increased heat transfer efficiency, the heat transfer coefficients obtained by the standard method increase in proportion to the average (over the hole surface) relative heat 
transfer coefficients. To take into account the increase in the heat exchange area, it is necessary to estimate its relative increase in $\mathrm{K}_{\mathrm{F}}$ and take it into account in the standard procedure.

For the proposed geometric parameters of hemispherical depressions, $\mathrm{K}_{\mathrm{F}}$ takes values from 1.09 to 1.116 , depending on the packing density (for a preliminary estimate, $\mathrm{K}_{\mathrm{F}}=1.1$ was taken in the calculations). The calculations showed that the flow regime is turbulent: $\mathrm{Re}$ $=69636.4$. For such a regime, with intensification on spherical intensifiers, we take [67] $\tilde{\alpha}=$ 1.25. The results of calculating the daily heat perception of a flat water-air collector with an increased heat transfer efficiency are summarized in Table 2.

Table 2. Results of calculating a flat reservoir (intensification: $\mathrm{K}_{\mathrm{F}}=1.1, \tilde{\alpha}=1.25$ ). Inlet air temperature / ambient temperature $0^{\circ} \mathrm{C}$

\begin{tabular}{|c|c|c|}
\hline № & $\begin{array}{c}\text { The local } \\
\text { time }\end{array}$ & $\begin{array}{c}\text { Warmth is } \\
\text { beneficially } \\
\text { perceived } \\
\text { collector, W }\end{array}$ \\
\hline 1 & $9: 00$ & 0 \\
\hline 2 & $10: 00$ & 152 \\
\hline 3 & $11: 00$ & 377 \\
\hline 4 & $12: 00$ & 590 \\
\hline 5 & $13: 00$ & 635 \\
\hline 6 & $14: 00$ & 675 \\
\hline 7 & $15: 00$ & 660 \\
\hline 8 & $16: 00$ & 595 \\
\hline 9 & $17: 00$ & 465 \\
\hline 10 & $18: 00$ & 267 \\
\hline 11 & $19: 00$ & 52 \\
\hline 12 & $20: 00$ & 0 \\
\hline 13 & Total per day & 4468 \\
\hline & & \\
\hline
\end{tabular}

The intensification showed a $2.43 \%$ increase in efficiency. The annual efficiency of reservoir intensification will be $106 \mathrm{~kW} / \mathrm{m}^{2}$. At the current tariff for the district heating system in Chita, 1925 rubles / Gcal, the economic effect is 175.5 rubles / $\mathrm{m}^{2}$.

\section{Discussion of the results}

To use the solar air heating installation scheme, it is necessary to calculate the collector. When calculating the solar collector of a solar air heating system, the initial data are: the parameters of the collector, the flow rate of the intermediate heat carrier and air, the characteristic of the time interval, as well as the outside air temperature. Based on the calculation of the storage tank, the temperature of the intermediate heat carrier at the outlet 
from it is determined. The result of the calculation is the temperature of the intermediate heat carrier at the inlet to the tank, as well as the air temperature at the outlet.

The basis for calculating the solar collector at a particular moment in time is the characteristic of the intensity of the actual solar radiation incident on the ray-receiving surface, taking into account its installation.

Thermal balance of the combined collector:

$$
Q_{\text {изл }}=Q_{\text {возд }}+Q_{n л}+Q^{\text {пот }}
$$

where $\mathrm{Q}_{\text {изл }}=I \cdot F$ - the amount of heat entering the effective area occupied by the receiver;

$Q_{\text {возд }}$ - the amount of heat received by the air flowing through the collector;

$Q_{n n}$ - the amount of heat received by the plate;

$Q^{\text {nom }}$ - heat loss to the environment.

In the general case, air receives heat due to the absorption of radiation energy and due to convective heat exchange with the ray-receiving plate:

$$
Q_{\text {возо }}=Q_{\text {возд }}^{u з л}+Q_{\text {возо }}^{\text {конв }}
$$

The amount of heat by radiation that has passed through a double transparent coating, assuming the properties of the coating are the same, and is beneficially perceived by both heat transfer fluids

$$
Q_{\text {пол }}=Q_{\text {изл }} \cdot D^{2}-Q^{\text {пот }}=Q_{\text {возд }}^{\text {изл }}+Q_{\text {возд }}^{\text {конв }}+Q_{n л},
$$

where $D$ - transparent coating transmittance.

Since the thickness of the air layer between the plate and the transparent coating is small,

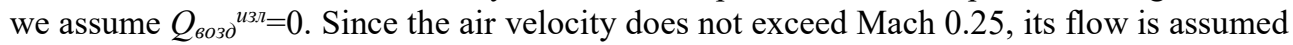
to be indistinguishable from the flow of an incompressible fluid.

Heating temperature of the radiation receiving plate $t_{n л}$ is a variable and depends on the characteristics of the collector and the current intensity of solar radiation. Mean $t_{n л}$ can be found subject to change $Q_{\text {изл }}$, reducing addiction $t=f\left(Q_{\text {изл })}\right)$ к $t=f(\tau)$, get:

$$
\bar{t}_{n л}=\left(\begin{array}{c}
\max \\
t_{n л}
\end{array}-t_{\text {возд-ночь }}\right) \cdot \sin \left(\frac{\tau-S_{\text {восход }}}{S_{\text {заход }}-S_{\text {восход }}}\right)+t_{\text {возд-ночь }}
$$

where $t_{\text {возд-ночь }}$ - air temperature at night.

The amount of heat absorbed by the air can be found using the method of successive approximations, the essence of which is that, having previously set the temperature of the air at the outlet, we find the total amount of heat:

$$
Q_{\text {возд }}=w_{\text {возд }} \cdot \rho_{\text {возд }} \cdot f_{\text {возд }} \cdot c_{\text {Рвозд }} \cdot\left(t_{\text {возд }}^{\text {нагр }}-t_{\text {окр }}\right) \cdot n,
$$

where $\quad w_{\text {возд }}$ - fan-determined air velocity in the duct with cross-section $f_{\text {возд; }}$;

$\rho_{\text {возд }}$ - air density;

$C_{\text {Рвозд }}$ - isobaric heat capacity of air;

$t_{\text {возд }}^{\text {нагр }}$ - temperature of the heated air at the outlet of the manifold;

$n$ - the number of parallel-connected radiation-receiving plates.

Or the amount of heat transferred by a heated plate to the air flowing along it in a given section of the plate: 


$$
d Q_{\text {возд }}^{\text {конв }}=\alpha_{\text {возд }} \cdot k_{F} \cdot b_{n л} \cdot\left(t_{n л}(l)-t_{\text {возд }}(l)\right) d l,
$$

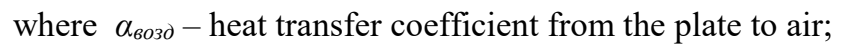

$b_{n n}$ - plate width;

$t_{n n}$ - plate temperature, variable along the length due to cooling by washing air;

$t_{\text {возо }}$ - heated air temperature;

$l-$ length of the radiation receiving area of the plate;

$k_{F}$ - the coefficient of the convective heat exchange area, taking into account the washing with air from both sides and the increase in the area due to intensification (corrugated or well). Integrating this equation along the length, we obtain $Q_{\text {бозд }}$ or, taking as a first approximation $t_{\text {возо }}(l)$, equal to the mean rhytmic temperature, or breaking the plate into sections.

After finding $Q_{\text {воз }}^{\text {конв }}$ by ur. (6) we compare it with the one obtained earlier and, if there is a discrepancy, we specify the air temperature at the outlet. If the values coincide, then we calculate the heat loss by radiation from the plate on both sides, taking into account double glazing, as well as the heat loss with reflected radiation.

$$
Q_{n \pi}^{\text {nom.omp }}=\left(1-\varepsilon_{i}\right) \cdot Q_{\text {изл }} \cdot n .
$$

Then we determine the amount of heat, as a result, perceived by the plate:

$$
Q_{n л}=Q_{\text {изл }} \cdot D^{2}-Q_{\text {возд }}-Q^{\text {пот }},
$$

The temperature of the intermediate heat carrier at the outlet of the collector is determined by ur. (9):

$$
\mathrm{Z}_{\mathrm{hor}}=\mathrm{x} \cdot \cos (\text { lat })+\mathrm{z} \cdot \sin (\text { lat })
$$

and the temperature at the inlet to the tank or to the first stage of the heater for air heating according to ur. (10):

$$
\mathrm{h}=\arcsin \left(\mathrm{z}_{\text {hor }}\right)
$$

Knowing the methodology for calculating the solar collector, we can use the scheme of an energy efficient solar air heating installation and implement it in air heating systems, which will significantly increase the efficiency of such systems, and we can also reduce the use of traditional heat sources.

\section{Conclusions}

Solar energy is the most affordable and widespread form of all existing energy resources. Many countries are actively pursuing policies to increase the share of solar energy use. However, the installation of conventional solar collectors is no longer so effective, therefore, various methods are being actively studied to improve the characteristics of solar collectors, which in turn leads to an increase in their performance.

Currently, a significant number of different schemes for using solar energy have been developed. The article proposes a method for using a regenerative air solar collector with increased heat transfer efficiency using hemispherical recesses as intensifiers. Testing of this 
method has shown its high efficiency due to increased intensification, and the economic effect of using this method is also clearly reflected. The use of solar heating with the use of solar collectors of various types in air heating systems will significantly increase the efficiency of such systems, as well as increase the degree of replacement of traditional heat sources.

\section{References}

1. Kommersant Magazine 2019; https://www.kommersant.ru/doc/3952751

2. Peretok.ru magazine 2014; https://peretok.ru/articles/freezone/17430/

3. V.A. Ageev Non-traditional and renewable energy sources: textbook. Manual for UNIVERSITIES, (2006)

4. G.P. Vasiliev G.P., Energy saving, 3, 63 (2008)

5. Materials of the Federal Industrial Association of Germany for household, energy and environmental technologies

6. C.H. Duncan, Solar Energy. 28, 385

7. R.E. Jones, Solar Energy. 24, 305

8. S.A. Klein, Solar Energy. 19, 325

9. R.V. Dunkle, "Thermal radiation Tables and Applications" Traurs ASME. 76, 549

10. S.A. Klein, W.A. Beckman. Journal of Solar Energy Engineering. 106, 1-10, (1984)

11. R.K. Aggarwal, Journal of Environmental Engineering and Technology, 2, 4-6, (2013)

12. R. Kumar, R.A. Gupta, A. K. Bansal, Swarm and Evolutionary Computation, 8, 33 (2013)

13. A. S. Al Busaidi, H. A Kazem, A. H Al-Badi, M. F. Khan, Renewable and Sustainable Energy Reviews, 53, 185-193, (2015)

14. A. Gonzales, J.-R. Riba, A. Rius, R. Puig. Applied Energy, 154, 752-762, (2015)

15. A. Fetanat, E. Khorasaninejad, Applied Soft Computing, 31, 196-209, (2015)

16. A. K. Yadav, S.S. Chandel, Applied Soft Computing, 75, 675-693, (2015)

17. G. M. Tina, S. Gagliano, Renewable Energy, 36, 1719-1727, (2011)

18. G. Bekele, G. Boneya, Energy Procedia, 14. P. 1760-1765, (2012)

19. O. Ekren, B. Y. Ekren. Applied Energy, 87, 592-598, (2010)

20. G. M. Tina, S. Gagliano, Renewable Energy, 36, 1719-1727, (2011)

21. D.N Karamov, Optimization of the equipment composition of autonomous power complexes using renewable sources and energy storage devices abstract dis, (2016)

22. M. Castaneda, A. Cano, F. Jurado, H. Sanchez, L. M. Fernandez, International Journal of Hydrogen Energy, 38, 3830-3845, (2013)

23. E.E. Anderson, Fundamentals of Solar Energy Conversion, Addison-Wesley, MA.

24. R.V. Dunkle, "Randomly Packed Partieulate Bed Regenerators and Evaporative Coolers" MCB, 117

25. W.W. Carfers, L.S. Peterson, Solar Energy, 13, 4

26. W.C. Swinbank, Q.J. Roy, Meteorol Soc, 89, 339

27. E.M. Sparow, J.W. Ramsey, E.A. Mass, Heat Transfer 101, 2

28. E.M. Sparow, NASA Tecnical Note 3331 
29. University of Minesota and Honeywel Corp, Progress Report No. 2 to National Seience Foundation, NSF/RANN/SE/GI-3487/PR/73/2

30. D.K. Edwards, J.T. Gier, K.E. Nelson, R.D. Roddik, J.T. Gier, Report No. 60-93 Departuuent of Engineering, University of California at Los Angeles

31. D.K. Edwards, J.T. Gier, K.E. Nelson, Roddik R.D, Solar Energy, 6, 1

32. D.N. Karamov, Optimization of the equipment composition of autonomous power complexes using renewable sources and energy storage dis. ... Candidate of technical sciences: 05.14.01 (2016)

33. 33. A. Kaabeche, M. Belhamel, R. Ibtiouen, Energy, 36, 1214-1222, (2011)

34. W. Wu, Y.-Y. Zhou, M.-H. Lin, J.-J. Hwang, Energy Conversion and Management, 74, 344-352, (2013)

35. G. Notton, S. Diaf, L. Stoyanov, Energy Procedia, 6, 666-677, (2011)

36. V.V.Butuzov. INCREASING THE EFFICIENCY OF SOLAR HEAT SUPPLY SYSTEMS abstract dis. All-Russian Scientific Research Institute for Electrification of Agriculture, (2013)

37. World Radiation Data Center URL: http://wrdc.mgo.rssi.ru/wwwrootnew/wrdc_ru_ne w.htm (date of access: 01.03.2016)

38. 38. S. V. Kiseleva, Geographic Information System (GIS) "Renewable Energy Sources of Russia".

39. A. Whiller, Solar Energy, 9, 164

40. D.J. Norris, Solar Energy, 12, 107

41. D.J. Norris, Solar Energy, 16, 53

42. Meteonorm Software . URL: http://meteonorm.com (date of access: 01.03.2016)

43. Local base of Europe and North Africa E.S.R.A. 2000. URL: www.ensmp.fr/Fr/Services/Presses ENS (date of access: 01.03.2016).

44. Local base of Europe and North Africa S @ tel - Light 2000. URL: www.satellight.com (date of access: 01.03.2016).

45. RetScreen. URL http://www.retscreen.net/ (date of access: 01.03.2016).

46. Climate 1. URL http:// www.climate-one.de/ (date of access: 01.03.2016).

47. F.-F. Li, J. Qiu, Applied Energy, (2015)

48. A. Mahesh, K. S. Sandhu, Renewable and Sustainable Energy Reviews, 52, 1135-1147, (2015)

49. Surface meteorology and Solar Energy. A renewable energy resource web site URL: https://eosweb.larc.nasa.gov/sse (date of access: 01.03.2016).

50. V.V.Butuzov. INCREASING THE EFFICIENCY OF SOLAR HEAT SUPPLY SYSTEMS dissertation ... Candidate of Technical Sciences: 05.14.08 / All-Russian Scientific Research Institute of Agricultural Electrification, (2013)

51. C.M. Kemp Apparatus for Utilizing the Sun's rays for heating water // US patent N 451384, 1891

52. V.A. Butuzov S.O.K. Journal, 12, (2013)

53. S. Banse Sun, Wind \& Energy, 2, (2012)

54. Tanja Peschel Commercial CSP plant in Saudi Arabia // Sun, Wind \& Energy, 13, (2016)

55. V.A. Butuzov, Journal of SOK, 14, (2014)

56. Roubcke I. Pool absorbers. Gautions optimist // Sun, Wind \& Energy, 7, (2010) 
57. V.A. Butuzov, E.V. Bryantseva, V.V. Butuzov, Gnatyuk I.S. Gnatyuk, Alternative energy and ecology, 2, 10-13, (2010)

58. N. Wang, T. Esram, L.A. Martinez, M.T. McCulley, Renewable Energy, 34, 2860-2871, (2009)

59. E. Moretti, E. Bonamente, C. Buratti, F. Cotana, Energies, 6, 5114-5129, (2013)

60. A. Osborne, S. Baur, K. Grantham, Solar House Energies, 3, 1251-1262, (2010)

61. S. Wermager, S. Wermager, S. Baur, Energies, 6, 6373-6390, (2013)

62. 62.[138] Khelifa, A., Touafek, K., Ben Moussa, H., Tabet, SOLAR ENERGY, 135, (2016)

63. Solar energy abroad. Energosovet magazine; <http://www.energosovet.ru/stat787.html>

64. R.V. Dunkle, "Thermal radiation Tables and Applications" Traurs ASME, 76, 549

65. R.V. Dunkle, "Randomly Packed Partieulate Bed Regenerators and Evaporative Coolers" MCB, 117

66. S.A. Klein, Solar Energy, 19, 325

67. S.G. Batukhtin, Improving the efficiency of energy systems and units of TPPs through the use of non-traditional and renewable energy sources: dis, 94 (2016) 